\title{
Plasma oxytocin levels are reduced in Slovak autistic boys
}

\author{
Lakatosova $\mathrm{S}^{1}$, Bakos $\mathrm{J}^{1,2}$, Pivovarciova $\mathrm{A}^{1}$, Husarova $\mathrm{V}^{1}$, Durdiakova $\mathrm{J}^{1}$, Bacova $\mathrm{Z}^{2}$, Kubranska \\ $\mathrm{A}^{1}$, Babinska $\mathrm{K}^{1}$, Ostatnikova $\mathrm{D}^{1}$ \\ Institute of Physiology, Faculty of Medicine, Comenius University, Bratislava, Slovakia. \\ silvia.lakatosova@gmail.com
}

\begin{abstract}
BACKGROUND: Oxytocin is a neuropeptide affecting social behaviour. Autism spectrum disorders are characterized by social deficits, impaired communication and repetitive behaviours. Several studies have shown reduced plasma levels of oxytocin and moreover, administration of oxytocin reduced clinical symptoms of autism. AIM: The aim of this study was to reveal differences in the plasma levels of oxytocin between autistic and healthy populations in Slovakia.

METHODS: After a signed consent, 108 autism spectrum disorder patients were enrolled in the study (83 males, 25 females). A control group of 131 healthy children was recruited (106 males, 25 females). Blood samples were obtained from all children and plasma oxytocin levels were measured using the ELISA method.

RESULTS: Oxytocin levels were lower in the boys older than 10 years of age in comparison to controls. There were no significant differences in oxytocin levels among girls. Oxytocin levels did not significantly correlate with age in either of the examined groups.

CONCLUSION: Decreased oxytocin levels in plasma of autism boys may be related to decreased sociability and social interactions. The addition of psychological profiling may reveal possible correlations of hormone levels with symptom severities (Tab. 1, Fig. 2, Ref. 23). Text in PDF www.elis.sk.

KEY WORDS: autism, oxytocin, social deficits.
\end{abstract}

\section{Introduction}

Oxytocin is a neuropeptide widely distributed in the central nervous system, promoting a high variety of effects on brain functions. Animal studies show that oxytocin plays a role in social interactions, attachment, pair bonding, sexual behaviour and social memory (1). Oxytocin knockout mice display social deficits such as impaired social recognition (2). Oxytocin receptor knockouts display deficits in ultrasonic vocalization in response to maternal separation in comparison to control mice (3).

Human studies confirm these prosocial characteristics of oxytocin observed in animal models. Oxytocin was found to improve several aspects of human social behaviour such as interpersonal trust (4), eye contact (5), and empathy measured as the ability to infer mental states of others (6).

Autism spectrum disorders (ASD) are characterized by social deficits, impaired communication and repetitive behaviours. Deficits in social behaviour are a core symptom of autism that

${ }^{1}$ Institute of Physiology, Faculty of Medicine, Comenius University, Bratislava, Slovakia, and ${ }^{2}$ Institute of Experimental Endocrinology, Slovak Academy of Sciences, Bratislava, Slovakia

Address for correspondence: S. Lakatosova, $\mathrm{PhD}$, Institute of Physiology, Faculty of Medicine, Comenius University in Bratislava, Sasinkova 2, SK-813 72 Bratislava, Slovakia.

Phone: +421.2.59357520, Fax: +421.2.59357515

Acknowledgements: Authors thank all the families with autism and control group children for their participation. Study was supported by the following grants: APVV-0253-10, APVV-0254-11, VEGA- 1/0066/12. makes an oxytocin system a major suspect in the pathogenesis of the disorder.

Several studies have shown altered plasma levels of oxytocin. Modahl et al (7) found reduced oxytocin levels in 29 pre-pubertal boys with autism compared to 30 age-matched controls in the US population. Green et al (8) have extended this study and have found an alteration in oxytocin peptide processing in this sample. Oxytocin plasma levels were decreased and levels of oxytocin Cterminal extended peptides were increased in autistic boys compared to healthy subjects. Oxytocin and vasopressin levels were found to be reduced in 77 autistic boys from central Saudi Arabia compared to the controls (9). Andari et al (10) found profoundly decreased oxytocin levels in 13 high functioning autistic patients compared to controls in a French population. Finally, a study focusing on peripheral neuropeptide levels revealed no differences in oxytocin and vasopressin levels among 75 autistic patients compared to age-matched controls in the US population (11).

In the last few years, a number of studies employing oxytocin administration in the treatment of mental illnesses emerged rapidly. Intranasal and intravenous oxytocin administration was shown to improve some of the clinical symptoms of autism, such as repetitive behaviours(12), increased social learning (13), increased social recognition and emotionality $(14,15)$, and improved social interaction in high functioning autistic patients (10).

Underlying the link between oxytocin and autism, the number of genetic studies have shown positive associations among polymorphism in genes encoding oxytocin and oxytocin receptors and autism employing family or population based approaches (16-21). 
659-661

Tab. 1. Plasma oxytocin levels in all examined groups of participants.

\begin{tabular}{llc}
\hline & Plasma oxytocin in boys & p value \\
\hline ASD & $208.1 \pm 26.68 \mathrm{pg} / \mathrm{mL} ; \mathrm{n}=80$ & 0.0248 \\
CTRL & $281.7 \pm 19.79 \mathrm{pg} / \mathrm{mL} ; \mathrm{n}=103$ & $*$ \\
\hline \multicolumn{3}{c}{ Plasma oxytocin in boys $\leq 10$ years of age } \\
\hline ASD & $213.1 \pm 30.50 \mathrm{pg} / \mathrm{mL} ; \mathrm{n}=64$ & 0.3512 \\
CTRL & $251.2 \pm 25.65 \mathrm{pg} / \mathrm{mL} ; \mathrm{n}=54$ & $\mathrm{~ns}$ \\
\hline \multicolumn{3}{c}{ Plasma oxytocin in boys $>10$ years of age } \\
\hline ASD & $188.4 \pm 55.49 \mathrm{pg} / \mathrm{mL} ; \mathrm{n}=16$ & 0.0428 \\
CTRL & $315.4 \pm 30.07 \mathrm{pg} / \mathrm{mL} ; \mathrm{n}=49$ & $*$ \\
\hline ASD & Plasma oxytocin in girls & 0.5058 \\
CTRL & $282.9 \pm 65.10 \mathrm{pg} / \mathrm{mL} ; \mathrm{n}=24$ & $\mathrm{~ns}$ \\
\hline
\end{tabular}

Levels are expressed as the mean \pm SEM. $n=$ number of participants in appropriate groups, $\mathrm{ns}=$ nonsignificant, $\mathrm{p}$ value statistics - unpaired $\mathrm{t}$ test.

The aim of the present study was to reveal differences in the plasma levels of oxytocin among autistic and healthy population in Slovakia.

\section{Methods}

The study was approved by the Ethical Committee at Faculty of Medicine, Comenius University in Bratislava.

After acquiring an informed consent, 108 autistic patients were enrolled into the study ( 83 males, 25 females). Boys were aged from: 2 years to 22 years (mean age $7 \pm 5$ years) and girls were aged from 2 to 22 years (mean age $7 \pm 6$ years). 131 healthy children (106 males, 25 females) were recruited as a control group. Boys in the control group were aged from 2 to 20 years (mean age $11 \pm 6$ years) and girls in the control group were aged from 2 to 25 years (mean age $10 \pm 8$ years). The diagnosis of childhood autism

A

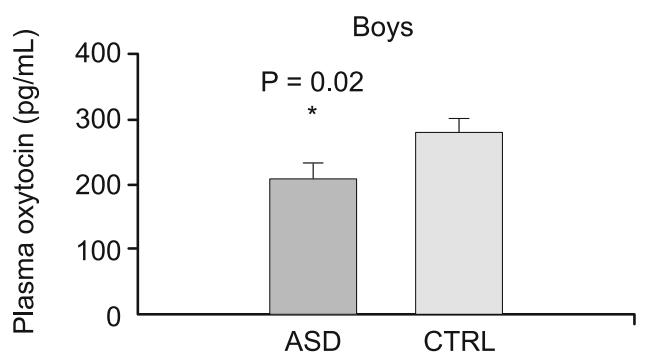

(B)

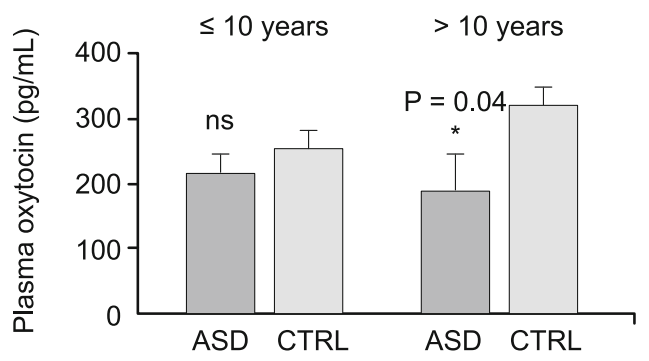

Fig. 1. A. Plasma oxytocin levels in boys. Values are expressed as the mean \pm SEM. B. Plasma oxytocin levels in boys divided into groups according to age. Values are expressed as the mean \pm SEM.

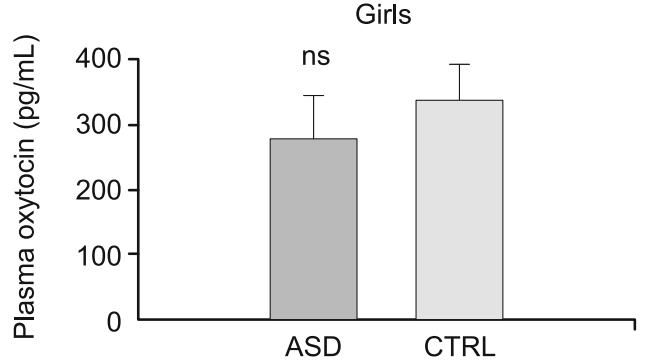

Fig. 2. Plasma oxytocin levels in girls. Values are expressed as the mean \pm SEM

was assessed by a psychiatristand clinical psychologist using the standard protocols (ICD-10, DSM-IV).

Blood samples were obtained from all children and the plasma oxytocin levels were measured using the ELISA method (Enzo Life Sciences). Differences in the oxytocin levels were evaluated using the unpaired t- test. Correlations of the plasma oxytocin levels with age were assessed using the Pearson correlation test.

\section{Results}

Children were divided into the groups according to age and gender; boys into the two groups (under 10 years and above 10 years).

The oxytocin levels were lower in the group of all boys, especially in the boys above 10 years of age, in comparison to controls (Tab. 1, Fig. 1). There were no significant differences in oxytocin levels among girls (Tab. 1, Fig. 2). The oxytocin levels did not significantly correlate with age in either of the examined groups. Autistic and control girls had higher oxytocin levels than boys, however, the differences were not significant (data not shown).

\section{Discussion}

In the present study, we have found decreased plasma oxytocin levels in boys with the diagnosis of autism in Slovakia compared to age-matched healthy controls. This significant difference emerged mostly due to reduced oxytocin levels in boys above ten years of age. However, we have not found any correlations of the oxytocin levels with age in any of the groups examined. Our results confirm results of the previous studies, which have found reduced plasma oxytocin levels in autistic boys (7-10).

Reduced oxytocin levels may explain profound social deficits, a core symptom of autism. However, peripheral peptide levels can hardly reflect brain oxytocin levels, expression, distribution and binding affinities of oxytocin receptors in the brain, which may be crucial for promoting prosocial effects of the oxytocin.

Reduction of the oxytocin levels may be due to lower oxytocin expression determined genetically. Other possibilities involve changes in enzymes involved in oxytocin synthesis or metabolism of oxytocin, which may be relevant in ASD pathogenesis (22).

We have found no differences in oxytocin levels in girls, possibly due to relatively small sample size. Girls had higher levels 
of plasma oxytocin than boys, however, the difference did not reach statistically significant levels. Other studies suggest a trend to increased plasma oxytocin levels in females (23). Expression of the oxytocin and its receptor is estrogen dependent, suggesting sex differences on the oxytocin system in humans (22). Active mechanisms employing estrogens together with the oxytocin and the oxytocin receptors may provide a protective milieu partially explaining the lower incidence of autism spectrum disorders in females.

Still increasing number of studies show that ASD is a complex condition involving many altered mechanisms. It is, therefore, probable that different autism traits may have several aetiologies. Profound social deficits are a core symptom in all ASD patients. Several studies have shown a correlation of social deficits with the oxytocin system, i.e. polymorphisms in the oxytocin receptor gene and/or altered plasma oxytocin levels $(7,20)$. Moreover, these social deficits seem to be at least partially improved after oxytocin administration in autistic patients $(10,13-15)$. A limitation of the present study is an absence of behavioural data in autistic patients. The addition of psychological profiling may reveal possible correlations of oxytocin levels with symptom manifestation and symptom severities in the children with autism in Slovakia.

\section{References}

1. Insel TR, O’Brien DJ, Leckman JF. Oxytocin, vasopressin, and autism: is there a connection? Biol Psychiatry 1999; 45 (2): 145-157.

2. Ferguson JN, Young LJ, Hearn EF, Matzuk MM, Insel TR, Winslow JT. Social amnesia in mice lacking the oxytocin gene. Nat Genet 2000; 25 (3): 284-288.

3. Takayanagi Y, Yoshida M, Bielsky IF et al. Pervasive social deficits, but normal parturition, in oxytocin receptor-deficient mice. Proc Natl Acad Sci U S A 2005; 102 (44): 16096-16101.

4. Kosfeld M, Heinrichs M, Zak PJ, Fischbacher U, Fehr E. Oxytocin increases trust in humans. Nature 2005; 435 (7042): 673-676.

5. Guastella AJ, Mitchell PB, Dadds MR. Oxytocin increases gaze to the eye region of human faces. Biol Psychiatry 2008; 63 (1): 3-5.

6. Domes G, Heinrichs M, Michel A, Berger C, Herpertz SC. Oxytocin improves ,,mind-reading“ in humans. Biol Psychiatry 2007; 61 (6): 731-733.

7. Modahl C, Green L, Fein D et al. Plasma oxytocin levels in autistic children. Biol Psychiatry 1998; 43 (4): 270-277.

8. Green L, Fein D, Modahl C, Feinstein C, Waterhouse L, Morris M. Oxytocin and autistic disorder: alterations in peptide forms. Biol Psychiatry 2001; 50 (8): 609-613.
9. Al-Ayadhi LY. Altered oxytocin and vasopressin levels in autistic children in Central Saudi Arabia. Neurosciences (Riyadh) 2005; 10 (1): 47-50.

10. Andari E, Duhamel JR, Zalla T, Herbrecht E, Leboyer M, Sirigu A. Promoting social behavior with oxytocin in high-functioning autism spectrum disorders. Proc Natl Acad Sci U S A 2010; 107 (9): 4389-4394.

11. Miller M, Bales KL, Taylor SL et al. Oxytocin and Vasopressin in Children and Adolescents With Autism Spectrum Disorders: Sex Differences and Associations With Symptoms. Autism Res 2013; 6 (2): 91-102.

12. Hollander E, Novotny S, Hanratty $M$ et al. Oxytocin infusion reduces repetitive behaviours in adults with autistic and Asperger's disorders. Neuropsychopharmacology 2003; 28 (1): 193-198.

13. Hollander E, Bartz J, Chaplin W et al. Oxytocin increases retention of social cognition in autism. Biol Psychiatry 2007; 61 (4): 498-503.

14. Guastella AJ, Einfeld SL, Gray KM et al. Intranasal oxytocin improves emotion recognition for youth with autism spectrum disorders. Biol Psychiatry 2010; 67 (7): 692-694.

15. Anagnostou E, Soorya L, Chaplin W et al. Intranasal oxytocin versus placebo in the treatment of adults with autism spectrum disorders: a randomized controlled trial. Mol Autism 2012; 3 (1):16.

16. Wu S, Jia M, Ruan Y et al. Positive association of the oxytocin receptor gene (OXTR) with autism in the Chinese Han population. Biol Psychiatry 2005; 58 (1): 74-77.

17. Jacob S, Brune CW, Carter CS, Leventhal BL, Lord C, Cook EH Jr. Association of the oxytocin receptor gene (OXTR) in Caucasian children and adolescents with autism. Neurosci Lett 2007; 417 (1): 6-9.

18. Lerer E, Levi S, Salomon S, Darvasi A, Yirmiya N, Ebstein RP. Association between the oxytocin receptor (OXTR) gene and autism: relationship to Vineland Adaptive Behavior Scales and cognition. Mol Psychiatry 2008; 13 (10): 980-988.

19. Yrigollen CM, Han SS, Kochetkova A et al. Genes controlling affiliative behavior as candidate genes for autism. Biol Psychiatry 2008; 63 (10): 911-916.

20. Wermter AK, Kamp-Becker I, Hesse P, Schulte-Körne G, Strauch $\mathbf{K}$, Remschmidt $\mathbf{H}$. Evidence for the involvement of genetic variation in the oxytocin receptor gene (OXTR) in the etiology of autistic disorders on high-functioning level. Am J Med Genet B Neuropsychiatr Genet 2010; 153B (2): 629-639.

21. Liu X, Kawamura Y, Shimada T et al. Association of the oxytocin receptor (OXTR) gene polymorphisms with autism spectrum disorder (ASD) in the Japanese population. J Hum Genet 2010; 55 (3): 137-141.

22. Carter CS. Sex differences in oxytocin and vasopressin: implications for autism spectrum disorders? Behav Brain Res 2007; 176 (1): 170-186.

23. Kramer KM, Cushing BS, Carter CS, Wu J, Ottinger MA. Sex and species differences in plasma oxytocin using an enzyme immunoassay. Canadian Journal of Zoology 2004; 82 (8): 1194-1200.

Received October 30, 2013. Accepted June 26, 2015. 